\title{
The use of adjuvants to local anesthetics: benefit and risk
}

Department of Anesthesiology and Pain Medicine, School of Dentistry, Kyungpook National University, Daegu, Korea

Young Hoon Jeon

A nerve block with local anesthetics is widely used for regional anesthesia or analgesia. Infiltration with local anesthetic around the nerve produces analgesia by interrupting pain signals to the brain. The analgesic effect of a nerve block with local anesthetics can last only a few hours. Therefore, after surgery patients may suffer from moderate to severe acute pain. The duration of the action of local anesthetic is prolonged by increasing the dose. But dose dependent side effects on the cardiovascular system or central nerve system can occur [1].

Therefore, perineural injection of adjuvants combined with local anesthetics has evolved for prolongation of the local anesthetic effect, without exhibiting the adverse effects common to opioids, epinephrine, dexmedetomidine or steroids. However, the use of adjuvants has been limited by their side effects [2].

For example, the use of opioids such as fentanyl or morphine increases the risk of respiratory depression, nausea and vomiting, and pruritus, especially when administered intrathecally or epidurally [3].

Epinephrine has vasoconstrictive properties, which prevent systemic reabsorption of local anesthetics, resulting in prolongation of local anesthetic action [4]. In addition, it can exert its analgesic effect mediated by activation of $\alpha-2$ adrenergic receptors [5]. However, the perineural administration of epinephrine may have detrimental effects on the nerve in patients with diabetes mellitus or hypertension [6].

Dexmedetomidine has a more selective $\alpha-2$ adrenergic receptor agonist than clonidine. It has been demonstrated that dexmedetomidine added to local anesthetics for the brachial plexus block increases the duration of local anesthetics, such as ropivacaine, and reduces the use of postoperative rescue analgesics. However, it has the potential side effects of hypotension and bradycardia [7].

Dexamethasone is a potent anti-inflammatory agent which has been investigated for its role as an adjuvant to local anesthetics. Recent evidences have shown that perineural use of dexamethasone in dose range of $4-8 \mathrm{mg}$ is effective in prolonging the local anesthetic action in a variety of blocks such as the epidural block, transabdominal block, and fascia iliaca block without any significant side effects $[8,9]$. However, there is controversy about whether perineural administration of dexamethasone is associated with its systemic effects [10].

In conclusion, adjuvants to local anesthetics should be explored in a variety of anesthesia practices in terms of patient satisfaction and safety. The concern regarding the safety of these adjuvants is caused by their potential risk of neurotoxicity. Therefore, further research is needed to investigate this problem. In addition, the exact mechanism of the analgesic action of adjuvants should be explored to

Received September 11, 2018. Accepted September 18, 2018.

Correspondence to: Young Hoon Jeon

Department of Anesthesiology and Pain Medicine, School of Dentistry, Kyungpook National University, 130 Dongdeok-ro, Jung-gu, Daegu 41944, Korea

Tel: +82-53-420-5863, Fax: +82-53-426-2760, E-mail: jeon68@gmail.com

(ㄷ) This is an open-access article distributed under the terms of the Creative Commons Attribution Non-Commercial License (http:// creativecommons.org/licenses/by-nc/4.0/), which permits unrestricted non-commercial use, distribution, and reproduction in any medium, provided the original work is properly cited.

Copyright (c) The Korean Pain Society, 2018 
increase analgesic efficacy and avoid adverse effects.

\section{REFERENCES}

1. El-Boghdadly K, Pawa A, Chin KJ. Local anesthetic systemic toxicity: current perspectives. Local Reg Anesth 2018; 11 : 35-44.

2. Kirksey MA, Haskins SC, Cheng J, Liu SS. Local anesthetic peripheral nerve block adjuvants for prolongation of analgesia: a systematic qualitative review. PLoS One 2015; 10: e0137312

3. Armstrong S, Fernando R. Side effects and efficacy of neuraxial opioids in pregnant patients at delivery: a comprehensive review. Drug Saf 2016; 39: 381-99.

4. Cazaubon Y, Mauprivez C, Feliu C, Binet L, Oget O, Gozalo $\mathrm{C}$, et al. Population pharmacokinetics of articaine with $1: 200,000$ epinephrine during third molar surgery and simulation of high-dose regimens. Eur J Pharm Sci 2018; 114: $38-45$.

5. Kumeta Y, Murata K, Kitahata LM, Aoki M, Nishio Y, Collins JG. Fentanyl suppression of nociceptive neurons in the superficial dorsal horn of the cat. Anesthesiology 1988; 69: 371-6.
6. Myers RR, Heckman HM. Effects of local anesthesia on nerve blood flow: studies using lidocaine with and without epinephrine. Anesthesiology 1989; 71: 757-62.

7. Abdallah FW, Brull R. Facilitatory effects of perineural dexmedetomidine on neuraxial and peripheral nerve block: a systematic review and meta-analysis. $\mathrm{Br} J$ Anaesth 2013; 110: $915-25$

8. Kim EM, Lee JR, Koo BN, Im YJ, Oh HJ, Lee JH. Analgesic efficacy of caudal dexamethasone combined with ropivacaine in children undergoing orchiopexy. $\mathrm{Br} J$ Anaesth 2014; 112: 885-91.

9. Wegner R, Akwar D, Guzman-Reyes S, Pednekar G, Chaudhry R, Grewal N, et al. Evaluating the adjuvant effect of dexamethasone to ropivacaine in transversus abdominis plane block for inguinal hernia repair and spermatocelectomy: a randomized controlled trial. Pain Physician 2017; 20: 413-8.

10. Desmet M, Braems $H$, Reynvoet M, Plasschaert S, Van Cauwelaert J, Pottel $H$, et al. I.V. and perineural dexamethasone are equivalent in increasing the analgesic duration of a single-shot interscalene block with ropivacaine for shoulder surgery: a prospective, randomized, placebocontrolled study. Br J Anaesth 2013; 111: 445-52. 